Bull. Mater. Sci., Vol. 36, No. 4, August 2013, pp. 535-539. (C) Indian Academy of Sciences.

\title{
Synthesis of copper telluride nanowires using template-based electrodeposition method as chemical sensor
}

\author{
SANDEEP ARYA, SALEEM KHAN, SURESH KUMAR ${ }^{\dagger}$, RAJNIKANT VERMA and \\ PARVEEN LEHANA* \\ Department of Physics \& Electronics, University of Jammu, Jammu 180 006, India \\ ${ }^{\dagger}$ Department of Electronic Science, Kurukshetra University, Kurukshetra 136 119, India
}

MS received 23 March 2012; revised 30 July 2012

\begin{abstract}
Copper telluride (CuTe) nanowires were synthesized electrochemically from aqueous acidic solution of copper (II) sulphate $\left(\mathrm{CuSO}_{4} \cdot 5 \mathrm{H}_{2} \mathrm{O}\right)$ and tellurium oxide $\left(\mathrm{TeO}_{2}\right)$ on a copper substrate by template-assisted electrodeposition method. The electrodeposition was conducted at $30^{\circ} \mathrm{C}$ and the length of nanowires was controlled by adjusting deposition time. Structural characteristics were examined using X-ray diffraction and scanning electron microscope which confirm the formation of CuTe nanowires. Investigation for chemical sensing was carried out

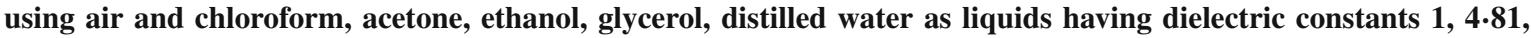
$8.93,21,24.55,42.5$ and $80 \cdot 1$, respectively. The results unequivocally prove that copper telluride nanowires can be fabricated as chemical sensors with enhanced sensitivity and reliability.
\end{abstract}

Keywords. CuTe; nanowires; electrodeposition; characterization; nanosensors.

\section{Introduction}

Nanosensors possess implausible potential in computing systems; and in near future, nanosensors may act as a bridge between various nano and macroscopic devices to exploit several advantages due to their unique physical properties (Lee et al 2005). The benefits of nano-based devices are their sensitivity which is better than conventional devices, fast response time, wide range of operations and portability. The fundamental core for intelligent nanosensors can be characterized for analysing power (Devreese and Eindhoven 2007). Depending on the field of application, nanosensors can be used for generating electrical, optical or thermal output signals that can be transformed into digital form for further processing. Accordingly, nanosensors can be classified as biosensors, chemical sensors and physical sensors, depending upon the area of application (Turner 2000; Lee and Kotov 2007; Pan et al 2008; Zhang and Johnson 2009). Several methods are reported to have been used for the fabrication of nanosensors (Suzuoki et al 1987; Caillaud et al 1993; Jin and Ying 1994; Inukai et al 1995; Mahmood et al 1995; Peulon and Lincot 1996; Hussain et al 2010). However, capacitive (chemical) sensors can be synthesized easily by using non-conductive material and are very much associated with the capacitor as its dielectric. Nanopore-based chemical sensors can detect the capacitance change with a very high sensitivity due to water adsorption (capillary condensation)

\footnotetext{
*Author for correspondence (pklehanajournals@gmail.com)
}

inside the nanopores because of its very high surface areato-volume ratio (An and Mai 2002). The value of the capacitance depends on dielectric constant of the material used and is in proportion to the frequency (Golonka et al 1997; Kim et al 2000; Steele et al 2004).

In this paper, template-based electrodeposition method was used to prepare CuTe nanowire sensors. Anodized aluminum oxide foil (AAO) acts as template and electrodeposition is conducted in a typical two-electrode cell with a platinum electrode in $50 \mathrm{ml}$ solution of electrolyte with copper foil acting as substrate for fabricating nanowires. After deposition, the as-prepared $\mathrm{CuTe}$ nanowires were extracted from the template by removing the AAO with an alkali solution. X-ray diffraction (XRD) and scanning electron microscopic (SEM) techniques have been used to characterize the nanowires. A careful analysis of the results shows the formation of defect-free CuTe nanowires in the form of parallel fibres. The nanowires obtained were characterized as sensors by using a simple application of a 555 IC timer as an astable multivibrator.

\section{Synthesis of nanowires}

A deep insight into the literature suggests the existence of two key methods for the synthesis of nanowires, viz. dry and wet processes. Dry processes include methods such as chemical vapour deposition (CVD), physical vapour deposition (PVD), pulse laser deposition (PLD), metal organic chemical vapour deposition (MOCVD) and molecular beam epitaxy (MBE) (Suzuoki et al 1987; Caillaud et al 1993; 
Jin and Ying 1994; Inukai et al 1995; Mahmood et al 1995; Peulon and Lincot 1996; Hussain et al 2010). Wet processes comprise sol-gel, hydrothermal, chemical bath deposition (CBD) and electrodeposition methods. Among these methods, electrodeposition has several advantages such as low cost, environment-friendly, high growth rate at relatively low temperatures and easy control of shape and size (She et al 2009). This template method is quite efficient in achieving controlled growth of nanowires; the physical shape, magnitude and orientation of the produced structures are precisely defined by the template. It allows the synthesis of simple and complex multi-segmented nanowire and coaxial nanowire structures. Electrodeposition depends on small but valuable factors such as surface characteristics of template, electrode substrate, $\mathrm{pH}$ value, mechanical agitation, temperature, etc. Morphology of the fabricated material depends on the pore morphology and dimensions (Chakarvarti and Vetter 1991).

\section{Experimental}

Copper telluride (CuTe) nanowires were synthesized by using template-based electrodeposition method as shown in figure 1.

It was carried out in a two-electrode electrochemical cell (Chakarvarti and Vetter 1991) as shown in figure 2. The commercially available self-adhesive copper tape (3 M 1181) was used as a substrate. The copper tape was fixed on the metallic base of the self-made electrochemical cell and it acts as cathode. Platinum $(\mathrm{Pt})$ electrode acts as anode.

Commercially available template with a porosity of 0.43 (Whatman Inc. $-100 \mathrm{~nm}$ diameter) was utilized to deposit $\mathrm{CuTe}$ nanowires. It was a precision membrane filter with a

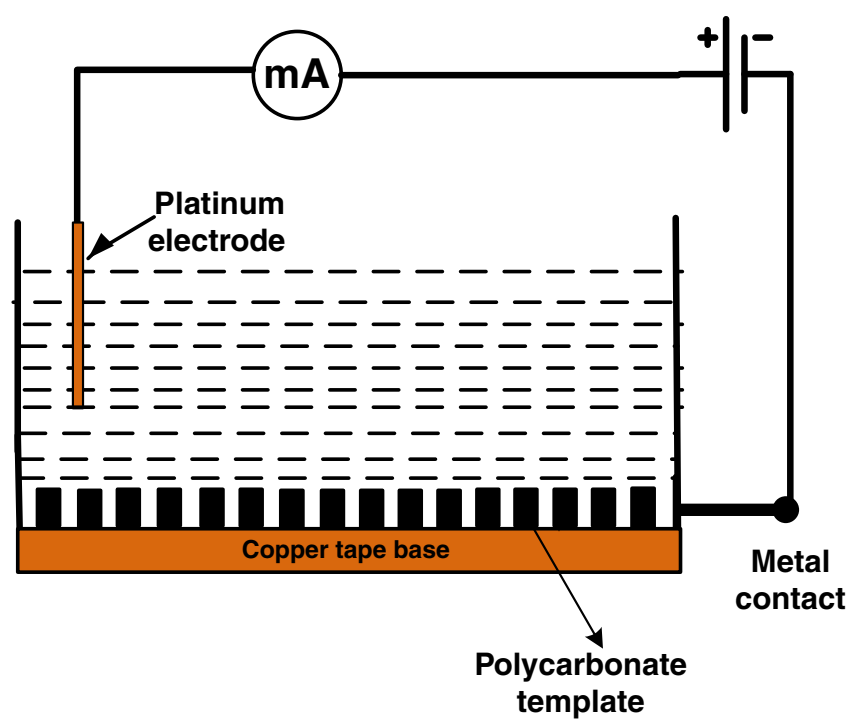

Figure 1. Schematic diagram for electrodeposition of $\mathrm{CuTe}$ nanowires.

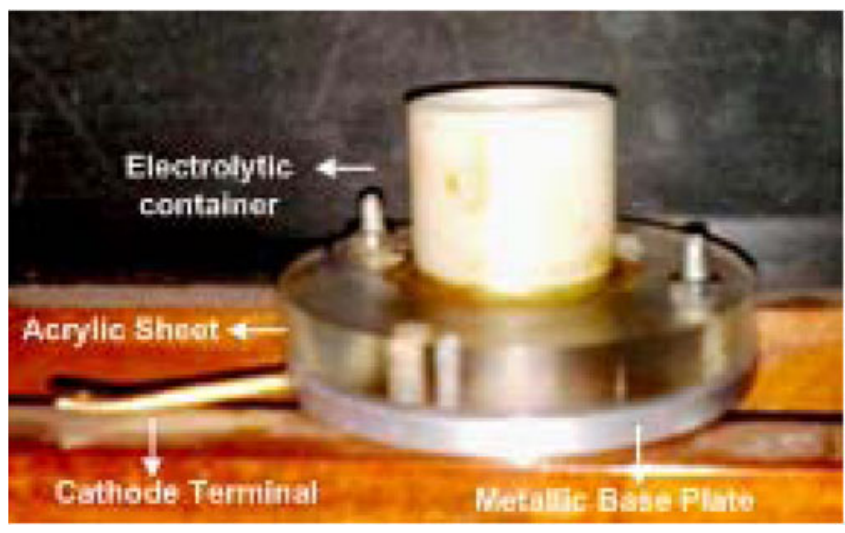

Figure 2. Electrochemical cell used for electrodeposition of $\mathrm{CuTe}$ nanowires.

closely controlled pore size distribution. It was fixed gently on the copper substrate through a rubber ring fitted in the top portion of the cell. Thus, an area of $\sim 1 \mathrm{~cm}^{2}$ on the copper substrate was allowed for exposure to the electrolyte through a nanoporous membrane. The system was tightly closed to ensure that no air bubble exists between membrane and substrate. The length of the nanowires was $6 \mu \mathrm{m}$ as it depended on the thickness of membrane used. Table 1 shows the specifications of commercially available membranes/templates for nanowire fabrication with varying sizes.

Electrolytic solution of about $50 \mathrm{ml}$ was used for nanowire synthesis. The electrolytic solution contained $0.2 \mathrm{M}$ of $\mathrm{CuSO}_{4} \cdot 5 \mathrm{H}_{2} \mathrm{O}, 0 \cdot 2 \mathrm{M} \mathrm{TeO}_{2}$ and $0.2 \mathrm{M} \mathrm{KOH}$ and was prepared in double distilled water at room temperature. $\mathrm{pH}$ value of the electrolytic solution was observed between 2.5 and 3.5. The electrolyte was poured in the cell and a voltage of $0.8 \mathrm{~V}$ was applied to the electrode through a variable d.c. power supply.

Mechanism for the formation of nanowires is shown in figure 3. As current passes through the solution, electrolysis takes place and $\mathrm{Cu}$ and $\mathrm{Te}$ atoms dissociate into positive ions and these ions move towards the cathode through the membrane pores and deposit on the $\mathrm{Cu}$ substrate in the nanoporous space.

The length of the nanowires was controlled by adjusting the time of deposition. As the nanowires grew, the nanopores of the template, typically AAO, were filled. Since the nanopores were perpendicular to the AAO membrane surface and were uniform in diameter and hexagonally packed, nanowires embedded in the template form were highly ordered and vertically aligned nanowire arrays (Prieto et al 2001). After deposition of nanowires on the substrate, the samples were detached from the cell and dried for half an hour. The sample was dipped in the aqueous solution of sodium hydroxide $(\mathrm{NaOH})$ for the removal of anodized alumina from the nanowires. Finally, the sample was dried at room temperature for further characterization.

During deposition process, high current was observed in the beginning that corresponds to the phenomenon of 
polarization. Thereafter, the current was found relatively steady and it served as an indication of the actual filling of the pores within the cell. This process required periodic monitoring to avoid overdeposition on the membrane surface. This led to successful fabrication of nanowires.

Morphology of the nanowires deposited on the $\mathrm{Cu}$ substrate was studied using SEM and XRD. Figure 4 shows SEM of CuTe nanowires which reveals that there is an optimum deposition of nanowires on the copper substrate with uniform growth and that the nanowires are vertically aligned with high aspect ratio.

The structural properties were studied using Panalytical X'PERT PRO Diffractometer using $\mathrm{Cu}-\mathrm{K} \alpha$ radiation at $45 \mathrm{~mA}, 45 \mathrm{keV}$. The XRD pattern was recorded in the range of 20 to 70 degree ( $2 \theta$ angle) with a step size of 0.01700 per second using $\mathrm{Cu}-\mathrm{K} \alpha$ radiation (wavelength), 1.5406 $\mathrm{A}$. Figure 5 shows the XRD pattern of $100 \mathrm{~nm}$ copper telluride nanowires on copper substrate.
The copper telluride $(\mathrm{Cu} 1.75 \mathrm{Te})$ nanowires are found to have hexagonal structure since the diffraction peaks in the patterns match with the standard ICDD copper telluride (Cu1.75Te) data file (JCPDS Number: 45-1287). A number of XRD peaks are obtained that are reflected from various planes (103), (108), (200) and (209) which confirm the formation of crystalline growth of copper telluride nanowires. A high intensity peak of copper is also observed in the XRD pattern indexed as (111) that appears due to copper substrate used.

The experimental set up for the characterization of sensing properties of CuTe nanowires is presented in figure 6. CuTe nanowires are assumed to be one plate of the capacitor while a simple copper substrate acts as another plate. Dielectrics used for the experiment are air, chloroform $\left(\mathrm{CHCl}_{3}\right)$, dichloromethane $\left(\mathrm{CH}_{2} \mathrm{Cl}_{2}\right)$, acetone $\left(\mathrm{CH}_{3} \mathrm{COCH}_{3}\right)$, ethanol $\left(\mathrm{C}_{2} \mathrm{H}_{5} \mathrm{OH}\right)$, glycerol $\left(\mathrm{C}_{3} \mathrm{H}_{8} \mathrm{O}_{3}\right)$ and distilled water $\left(\mathrm{H}_{2} \mathrm{O}\right)$, respectively.

Table 1. Standard specifications of different membranes/templates.

\begin{tabular}{|c|c|c|c|c|}
\hline Material & $\begin{array}{l}\text { Pore size } \\
(\mu \mathrm{m})\end{array}$ & $\begin{array}{l}\text { Diameter } \\
(\mathrm{mm})\end{array}$ & $\begin{array}{l}\text { Thickness } \\
(\mu \mathrm{m})\end{array}$ & $\begin{array}{l}\text { Pore density } \\
\left(\text { pores } / \mathrm{cm}^{2}\right)\end{array}$ \\
\hline Polyester & $0 \cdot 1-5 \cdot 0$ & $13,25,47$ & $9-23$ & $\begin{array}{l}10^{5} \\
- \\
6 \times 10^{8}\end{array}$ \\
\hline Polycarbonate & $0 \cdot 01-12 \cdot 0$ & $\begin{array}{l}13,19,25, \\
37,47,50, \\
76,90,142,293\end{array}$ & $7-20$ & $\begin{array}{l}10^{5} \\
- \\
6 \times 10^{8}\end{array}$ \\
\hline Aluminium oxide & $0 \cdot 02-0 \cdot 2$ & $13,21,47$ & 60 & $\begin{array}{l}10^{5} \\
- \\
6 \times 10^{8}\end{array}$ \\
\hline
\end{tabular}
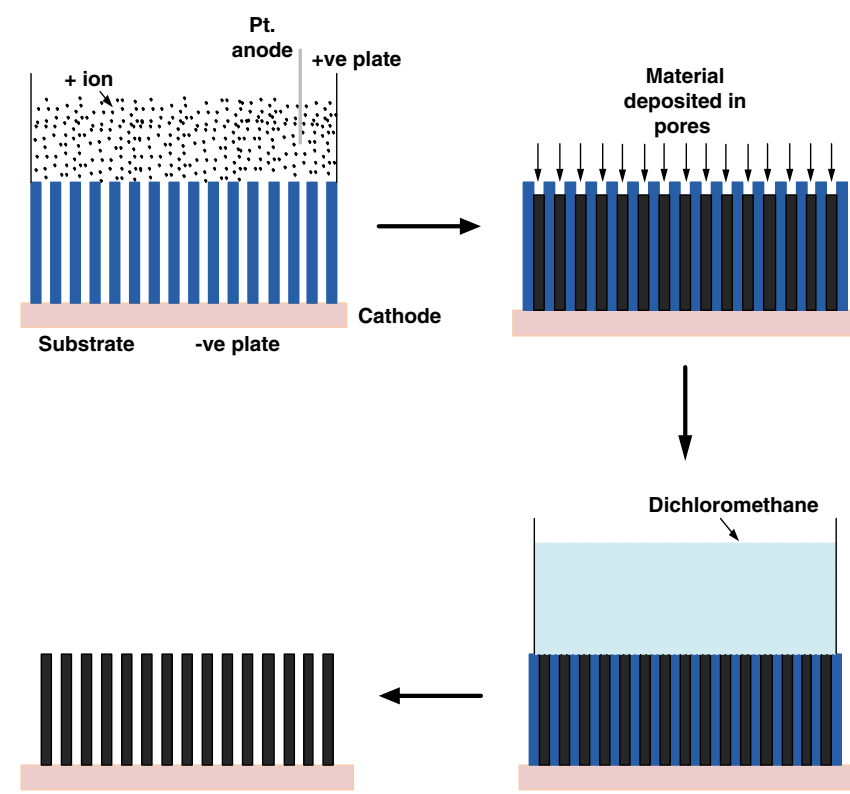

Figure 3. Schematic showing formation of CuTe nanowires by electrodeposition method.

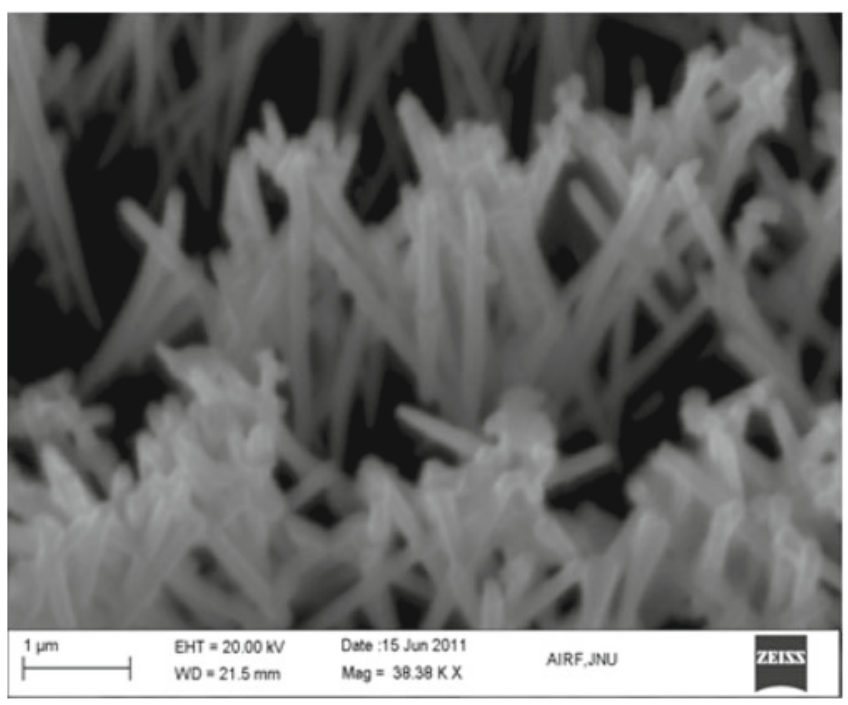

Figure 4. SEM of $100 \mathrm{~nm} \mathrm{CuTe}$ nanowires deposited on $\mathrm{Cu}$ substrate. 
The connections were made as per the circuit diagram using the application of a 555 timer as an astable multivibrator. The foils were separated by some specific distance $(\mu \mathrm{m})$ between them to be filled by different dielectric chemical liquids. The output was observed on a cathode ray oscilloscope (CRO). Mathematically, using a 555 timer as an astable multivibrator, the overall period of oscillations is given by

$$
T=0.693\left(R_{\mathrm{A}}+2 R_{\mathrm{B}}\right) * C,
$$

where $R_{\mathrm{A}}=10 \mathrm{k} \Omega$ and $R_{\mathrm{B}}=220 \mathrm{k} \Omega$.

The frequency of oscillation being the reciprocal of overall period of oscillation, $T$ and is given by

$$
f=\frac{1}{T}=\frac{1.44}{\left(R_{\mathrm{A}}+2 R_{\mathrm{B}}\right) * C} .
$$

The capacitance can be calculated as

$$
C=\frac{T}{0 \cdot 693\left(R_{\mathrm{A}}+2 R_{\mathrm{B}}\right)} .
$$

This method is used for calculating the capacitance after using CuTe nanowires as one of the capacitor plates.

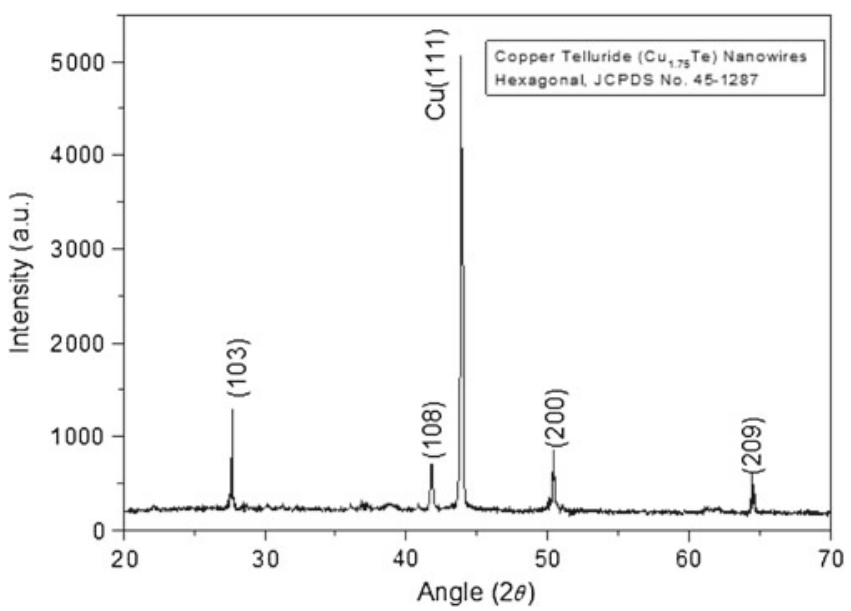

Figure 5. XRD pattern of copper telluride nanowires $(100 \mathrm{~nm})$ on $\mathrm{Cu}$ substrate.

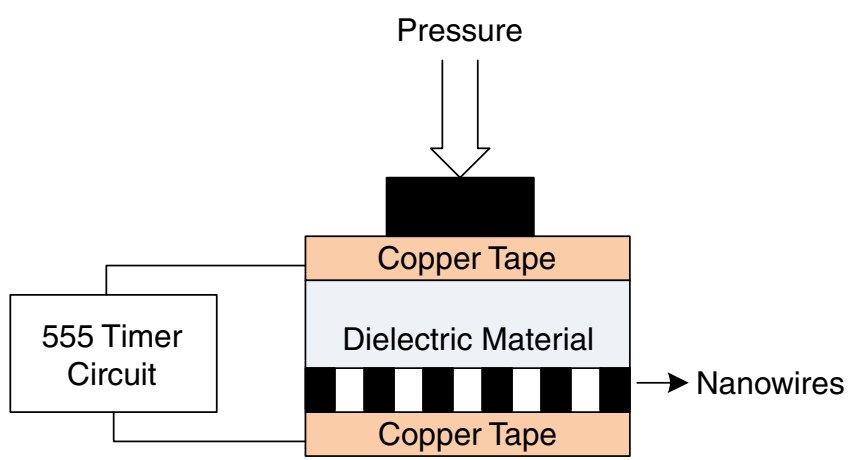

Figure 6. Experimental set up of $\mathrm{CuTe}$ nanowires as chemical sensor.

\section{Results and discussion}

Different capacitance values have been observed for $\mathrm{CuTe}$ nanowires fabricated on the copper substrate. A considerable change in the capacitance of $\mathrm{CuTe}$-based nanowires as capacitor illustrates its chemical sensing property for different dielectric materials (chemical liquids). Capacitance values estimated for different liquids are shown in table 2.

A plot of these values is shown in figure 7. It has been observed that capacitance changes with change of dielectric materials. As the dielectric constant of different (dielectric materials) liquids varies, so do the capacitances of $\mathrm{CuTe}$ nanowires. From figure 7, it is observed that capacitance of the CuTe nanowires on $\mathrm{Cu}$ substrate can sense different liquids effectively and it is further substantiated by the fact that capacitance changes with respect to the dielectric constant. The maximum and minimum values of capacitance were observed for water and chloroform, respectively. The capacitive effect in the CuTe nanowires may be due to the increase in surface area of nanowire-based capacitor.

A detailed analysis of the change in capacitance in different dielectric materials (chemicals) indicates that the change in capacitance is directly proportional to the dielectric constant. The value of the capacitance is observed as a function

Table 2. Variation in capacitance for different dielectric materials.

\begin{tabular}{lcc}
\hline $\begin{array}{l}\text { Dielectric } \\
\text { material }\end{array}$ & $\begin{array}{c}\text { Dielectric } \\
\text { constant }\end{array}$ & $\begin{array}{c}\text { Capacitance } \\
(\mathrm{pF})\end{array}$ \\
\hline Air & $1 \cdot 00$ & $16 \cdot 00$ \\
Chloroform & $4 \cdot 81$ & 25.60 \\
Dichloromethane & 8.93 & 27.82 \\
Acetone & 21.00 & 32.00 \\
Ethanol & 24.55 & 35.16 \\
Glycerol & 42.50 & 41.56 \\
Water & 80.10 & 48.00 \\
\hline
\end{tabular}

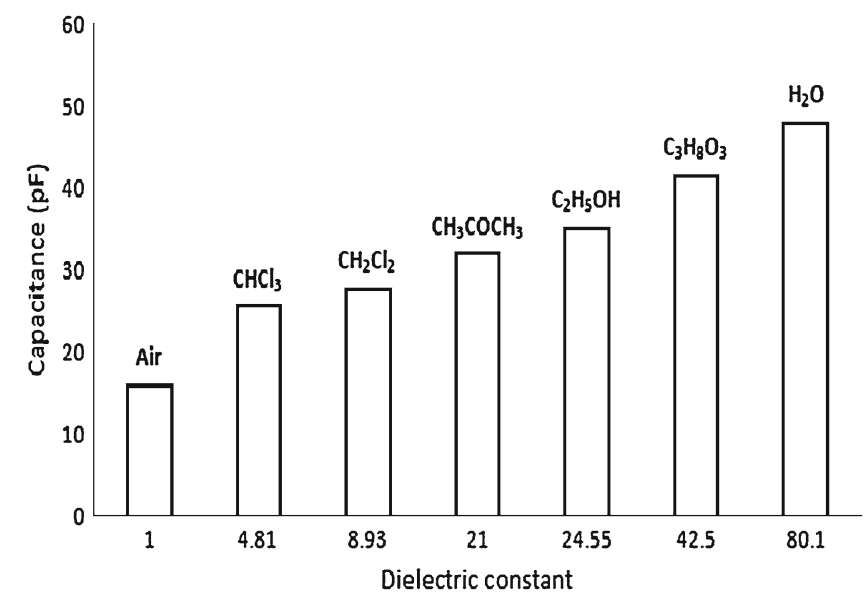

Figure 7. Variation in capacitance $(\mathrm{pF})$ for different chemical liquids used as dielectric. 
of its surface area, distance between the two plates of capacitor and the dielectric medium. It means that the nanowirebased capacitor can be used as a chemical sensor for sensing different fluids or liquids.

\section{Conclusions}

It is a simple and an economical method for fabricating highly ordered single crystalline CuTe nanowires of $100 \mathrm{~nm}$ diameter. The nanowires have been successfully characterized as sensors at room temperature. Investigations show that CuTe nanowire-based liquid sensors can be easily fabricated with enhanced properties such as sensitivity and reliability. The sensing property of CuTe nanowires as a capacitor shows change in the capacitance in accordance with the dielectric constant of the liquid used. Future studies will incorporate facilities of smart sensors in nanowire-based structures.

\section{References}

An D K and Mai L H 2002 Proc. IEEE Sensors 1633

ASTM Data File Nos. 45-1287, 32-0458

Caillaud F, Smith A and Baumard J F 1993 J. Am. Ceram. Soc. 76 998
Chakarvarti S K and Vetter J 1991 Nucl. Instrum. Meth. Phys. Res. B62 109

Devreese J T and Eindhoven T U 2007 Feynman's visionary 1959 Christmas Lecture 4

Golonka L J, Licznerski B W, Nitsch K and Teterycz H 1997 Meas. Sci. Technol. 892

Hussain M, Mazhar M, Hussain T and Khan N A 2010 J. Iran. Chem. Soc. 7 S59

Inukai T, Matsuoka M and Ono K 1995 Thin Solid Films 25722

Jin M and Ying L S 1994 Thin Solid Films 23716

Kim S J, Park J Y, Lee S H and Yi S H 2000 J. Phys. D: Appl. Phys. 331781

Lee J and Kotov N A 2007 Nano Today 248

Lee J, Govorov A O and Kotov N A 2005 Angew. Chem. 44 7439

Mahmood F S, Gould R D, Hassan A K and Salih H M 1995 Thin Solid Films 270376

Pan H, Cui R and Zhu J-J 2008 J. Phys. Chem. B112 16895

Peulon S and Lincot D 1996 Adv. Mater. 8166

Prieto A L, Sander M S, Martin-Gonzalez M S, Gronsky R, Sands T and Stacy A M 2001 J. Am. Chem. Soc. 1237160

She G, Mu L and Shi W 2009 Recent Patents Nanotechnol. 3182

Steele J J, Harris K D and Brett M J 2004 Mater. Res. Soc. Symp. Proc. 788 L11.4.1

Suzuoki Y, Ohki A, Mizutani T and Ieda M 1987 J. Phys. D20 511

Turner A P F 2000 Science 2901315

Zhang C-T and Johnson L W 2009 Anal. Chem. 813051 